\title{
ETNOTECNOLOGIA, AMAZÔNIA E CULTURAS
} DIGITAIS

\author{
Ricardo Damasceno MOURA ${ }^{1}$ \\ Instituto Federal do Pará \\ interaarte@hotmail.com
}

Resumo: $O$ texto aborda aspectos da etnotecnologia cultural como fonte de produção de recursos e inclusão social. Tal visão nos leva a fazer uma análise da tecnologia como um fenômeno eminentemente contemporâneo, buscando encerrar os elementos que a constituem e a definem. Em seguida realizamos uma pesquisa sobre a sua própria distribuição. Buscamos mapear suas definições e suas principais matrizes teóricas de análise, tanto no âmbito político, quanto no âmbito educacional. De posse desses elementos, procuramos identificar como a tecnologia interage com a cultura local e com a sustentabilidade na Região Amazônica. Por fim, buscamos identificar as políticas de inclusão digital assumidas mais diretamente pelo Brasil, em especial na Amazônia. A partir daí, estabelecemos uma abordagem comparativa que nos permitiu identificar as especificidades locais, reconhecer os pontos de acesso $e$ as dificuldades das localidades distantes, bem como identificar as identidades lá existentes no presente esforço de construção de um novo pensamento sobre patrimônio bio-diverso e conhecimento tradicional.

Palavras-chave: Etnotecnologia. Inclusão digital. Biodiversidade cultural.

Abstract: The text approaches aspects of the cultural etnotecnologia as source of production of resources and social inclusion. Such vision in takes them to make an analysis of the technology as a phenomenon eminently contemporary, searching to lock up the elements that constitute it and they define it. After that we carry through a research on its proper distribution. We search to maper its definitions and its main theoretical matrices of analysis, as much in the scope politician, how much in the educational scope. Of ownership of these elements, we look for to identify as the technology interacts with the local culture and the sustentabilidade in the Amazon region. Finally, we search to more directly identify the assumed politics of digital inclusion for Brazil, in special in the Amazon. From then on, we establish a comparative boarding that in allowed to identify them the local specificities, to recognize the points of access and the difficulties of the distant localities, as well as

${ }^{1}$ Pedagogo, coordenador do Projeto Tecnologia Para Todos. 
identifying to the there existing identities in the present effort of construction of a new thought on bio-diverse patrimony and traditional knowledge.

Keywords: Etnotecnologia. Digital inclusion. Cultural biodiversity. Sofware exempt.

\section{Introdução}

O objetivo do presente artigo é apresentar um estudo sobre a forma como se configura a aquisição tecnológica na Amazônia. Como combinar novas tecnologias, memória coletiva e culturas comunitárias. A tecnologia ampliou de forma inédita as fontes de produção, permitindo um avanço no campo planetário, na maneira de produzir sustentavelmente e competir, a exemplo da transformação do óleo da copaíba e da andiroba em produto lucrativamente sustentável. Para que no bojo desse processo, ocorra uma continuidade capaz de propiciar a discussão sobre o que é patrimônio bio-diverso, devemos perceber que a primeira matéria-prima do espaço amazônico é a informação, pois é por meio dela que ocorrerá uma penetrabilidade consciente em seus recursos. Antes de instar uma abordagem diferente, é preciso observar as formas como a comunidade por si se desenvolve. Na Amazônia é de fundamental importância o enfoque comunitário (pensar numa comunidade inteira e não somente em grupos isolados).

O grande desafio é encontrar formas de potencializar recursos. A carência de grupos organizados na Amazônia é o que mais dificulta esse processo. $\mathrm{O}$ artigo então aprimora um novo contexto, levantando formas de intervenção como a elaboração de projetos. Sabendo que os amazônidas, além de toda exclusão, consequência de uma globalização seletiva, têm dificuldade de elaborar projetos, sendo que alguns municípios mais afastados não têm sequer acesso à internet. Existe uma grande dificuldade de informação e apoio técnico nos locais onde se realizou a pesquisa.

Não apresento aqui uma solução ingênua ou otimista, pois em nenhum momento os dados apresentados na pesquisa se isentam de aspectos políticos e sociais, mas encontram argumentos alicerçados na sistematização de ações de extensão universitária.

Segundo estudo do Comitê Gestor da Internet no Brasil, o uso das tecnologias contribuem para promover o debate, criar soluções para que 
o setor público possa planejar seus programas de inclusão digital. Isso porque, no século XXI, é preciso garantir acesso ao conhecimento para superar a exclusão social e econômica.

\section{Etnotecnologia, um desafio para a amazônia}

Mas o que vem a ser etnotecnologia? Onde se fundamenta tal termo? O conceito etnotecnologia restabelece o respeito às diferenças, ampliando a significação do habitat de populações indígenas e quilombolas indo de encontro com a proposta de se repensar uma inclusão digital de fato para essa região. Há de se pensar, também, de forma geral, quais são os benefícios e as implicações da tecnologia nas relações sociais na Amazônia. A etnotecnologia passa pela questão indígena e afrodescendente, as identidades são únicas, porém indissociáveis. Mas o objetivo primeiro deste estudo é partir de uma análise para a inserção da tecnologia na cultura local dos ribeirinhos. Inicia-se, a partir desta pesquisa, um processo que envolve relações entre coletividades distintas em um mesmo espaço e pode ser comparada ao termo "etnologia", que não trata tão-somente da cultura material dos povos, mas, sobretudo, da forma de interação entre grupos culturais atuando em contextos sociais comuns.

O que observamos em todo o mundo é uma distância crescente entre globalização e identidade, entre a cultura digital e os amazônidas. Tal abordagem requer um conhecimento preciso das comunidades que habitam este território imerso pela floresta. Partindo dessas considerações, a identidade é o processo pelo qual um ator social se reconhece e constrói significado, principalmente com base em determinado atributo cultural ou conjunto de atributos, a ponto de excluir uma referência mais ampla a outras estruturas sociais.

Segundo Pretto (2008), a representação da identidade como afirmação cultural não significa necessariamente incapacidade de relacionar-se com outras ou abarcar toda a sociedade sob essa identidade. Nesse sentido, considero importante mencionar desde já que entendo representação como um processo de significação histórica. Um estudo mais profícuo, evocado por Lemos (2002), refere-se à identidade como uma riqueza que está sempre ligada à complexidade das diversas culturas, 
por onde circula a criatividade e a originalidade de um determinado povo.

Afirmo, em companhia de um crescente número de estudiosos, que a inserção de novas tecnologias na Amazônia precisa vir acompanhada de geração de emprego e renda, como é o caso do Amazon Paper, que através da organização de pequenos produtores valoriza o uso sustentável dos recursos naturais, ampliando a geração de emprego e renda para as populações pobres da Amazônia.

Como procedimento de pesquisa fizemos um levantamento em telecentros de Belém, nos bairros do Guáma e Terra-Fime, em especial, no localizado nas dependências da Empresa Copala, em 2008. Além disso, buscamos informações de como o processo de aquisição tecnológica acontece de fato em municípios afastados de Belém. Entre os projetos abordados nesta pesquisa, procuramos dar ênfase ao Projeto de Inclusão Digital do IFPA/PA, antes CEFET. Com o objetivo de detectar o nível de aquisição de tecnologia, segundo os aspectos técnicos e educacionais entre os envolvidos, foi providenciado um acompanhamento do Projeto, com observação participante e entrevista com os alunos, especialmente os que em algum momento dentro ou fora do telecentro presenciassem ou participassem de situações que envolvessem questões ligadas à valorização da comunidade.

A observação participante é aqui entendida como a entrevista por vezes instigada pelo entrevistador quando julga necessário para um melhor entendimento daquilo que está sendo relatado pelo entrevistad. Com os alunos foi muito necessário, porque muitas respostas foram dadas através de gestos e olhares que precisavam ser devidamente explicados.

O telecentro, cenário da pesquisa, desenvolve trabalho de educação digital e artes, GUAMARTE, com jovens na faixa etária compreendida entre 14 a 24 anos, por meio de cursos de capacitação na área de informática e artes visuais, e busca através deste trabalho iniciar um processo de coletivização, baseado numa consciência para a formação da cidadania.

Segundo o instrutor, o projeto já atendeu alunos ribeirinhos da Ilha do Combú e municípios adjacentes de Belém. A visita se estendeu por três meses sendo que nos dois primeiros, apenas entrevistas em períodos de aproximadamente uma hora, no terceiro dia, em período 
mais extenso. Além da visita com a autorização dos instrutores, houve interação com os alunos, naquilo que se pode chamar de entrevista, mas que, devido a pouca escolaridade deles, aqui será denominada como observação participante.

O telecentro é composto, em seu quadro funcional, por um coordenador, que se envolveu apenas nas questões administrativas e burocráticas, e instrutores do Curso de Tecnologia de Sistemas e Pedagogia/IFET/PA. Com relatos variando desde situações inusitadas, propriamente ditas, até experiências análogas vivenciadas em outros períodos e lugares, o que ficou bastante evidente foi a clara percepção dos instrutores quanto à necessidade de discutir a politização das tecnologias por meio de uma articulação entre cultura digital e educação. Vale ressaltar que é perfeitamente entendido que, em um telecentro, é crucial que se faça um trabalho educacional que possa gerar aprendizagens significativas a contento de todos. Como insiste Freire (2001), formar é muito mais do que treinar o aluno em certas destrezas. Para ele, ensinar não é transferir conhecimento, mas sim criar as possibilidades para a sua produção ou sua construção.

Os relatos feitos pelos instrutores demonstraram uma profunda preocupação com o tema inclusão digital, pois no final do ano os mesmos levaram seus alunos para participar da $7^{\mathrm{a}}$ Oficina de Inclusão Digital promovida pelo Ministério do Planejamento, visando aproximá-los do tema, segundo um instrutor, "nós trabalhamos com a conscientização prévia da importância do acesso às novas tecnologias para o mundo do trabalho".

O instrutor aplica no telecentro, para o trabalho prévio de conscientização, a atualização do blog "Cultura Guamaense" que, segundo ele, "trabalha muito bem com a questão da valorização da cultura, como identidade dentro de uma cultura local". As experiências vividas e presenciadas pelos instrutores e relatadas na entrevista variam de situações, como o contato com as manifestações culturais pela internet (é o caso do Grupo Canavalesco Bole-Bole).

Durante a pesquisa reconhecemos a importância do projeto, pois está diretamente ligado à questão da etnotecnologia, retratando consideráveis mudanças ocorridas na vida dos ribeirinhos que frequentavam o curso de iniciação à informática. 
A entrevista com vários alunos, de idade entre quatorze e vinte quatro anos, versou sobre conceitos de tecnologia. Segundo o instrutor, a faixa etária foi escolhida pela facilidade na comunicação e compreensão daquilo que estava sendo perguntado e também respondido, o que não impediu que em alguns momentos a pergunta tivesse que ser reformulada várias vezes até que se configurasse uma situação marcante na vida deles.

Uma das entrevistadas, residente na Ilha do Combú, 18 anos, estava bastante tímida, falava baixo e parecia ter receio de falar do assunto, o que foi totalmente diferente com os alunos residentes em Belém, que em tom bastante descontraído falaram sobre a importância da tecnologia, disseram que utilizam a internet para bate-papo e para conhecer novas culturas. A última aluna entrevistada, 24 anos, com traços indígenas, pois assim definiu-se, falou sobre igualdade digital, bastante polida e cuidadosa nas palavras e aparentemente muito informada sobre a questão, disse não se importar com a forma de acesso, o que importa "é que as pessoas consigam se inserir tecnologicamente".

\section{Cultura digital: caminhos para a integração}

Ao analisarmos o conceito de cultura como uma invenção das classes dominantes percebemos seus contrastes. Mas o que significa cultura? Durante a pesquisa cataloguei pouco mais de 150 definições que atestam a definição da palavra. Cultura é uma dessas palavras metafóricas (como, por exemplo, liberdade) que deslizam de um contexto para o outro, com significações diversas, e a mais importante é sua significação social, que é o que veremos mais adiante. Nosso objetivo é demonstrar o termo cultura, etnicamente relacionado com a criação de redes sociais. O conceito que se interconecta com o digital, proposto de cultura, é de "expansão" não como elemento de relação de poder preconizado pelo capitalismo. Com a propagação das novas tecnologias na Amazônia querse apenas mostrar que outras perspectivas são possíveis para as múltiplas culturas que lá se legitimam. Para compreender como a tecnologia pode se difundir na Amazônia é importante levar em conta o caráter das novas tecnologias (em especial sistemas de comunicação e informática 
acessíveis e de baixo custo) por se basearem nos conhecimentos armazenados, terem um potencial além da fonte se associado aos conhecimentos tradicionais. Simbolicamente, é preciso esforços no sentido de implementar redes globais de cultura digital. Hoje as pessoas precisam se ver e serem vistas pelo mundo. De fato, há uma integração dos povos que se reconhecem através da formação de redes, contrariamente, subvertendo-se ao conceito ocidental tradicional de sujeitos separados e independentes.

Primo (2007) destacou que, mais do que apoio governamental, o sucesso das iniciativas de inclusão digital depende diretamente da sua aplicabilidade. Em primeiro lugar, para começar uma discussão precisamos entender melhor o conceito de Democratização da informática (a quem se destina) e fazermos um paralelo com as políticas de TIC's. Mas a discussão sobre Democracia se estende e vai além do simples discurso. Faço então uma provocação, existe de fato essa democracia? Que inclusão é essa? Inclusão digital significa, antes de tudo, melhorar as condições de vida de determinada região ou comunidade com ajuda da tecnologia.

Em termos concretos, incluir digitalmente não é apenas "alfabetizar" a pessoa em informática, mas também melhorar os quadros sociais a partir do manuseio dos computadores. Como fazer isso? Mostrando como a população pode gerar conhecimento através das tecnologias digitais. Há uma série de iniciativas que merecem destaque como exemplo de Projetos de extensão universitária, que ilustram como o acesso às tecnologias e um pouco de criatividade podem mudar o cenário de pobreza.

Em Curralinho, no Marajó um grupo de estudantes de engenharia da Computação instalou estações de trabalho, cujos computadores funcionam por energia solar, já que não havia energia elétrica. Também não havia infraestrutura de telecomunicações, ou seja, nada de telefones ou conexões à internet. Então começaram a usar conexão via satélite, cujo valor ainda é bem alto. Ocorre que toda a parafernália pode ser tornar autosustentável.

Para Ferreira (2003), os governos dão pouca atenção na forma como a tecnologia pode fazer a diferença ou desconfigurar hábitos e costumes. Na mesma direção, Rebêlo (2008), discutindo a obra Sociedade em Rede 
de Manuel Castels, entende que o uso progressivo das possibilidades interativas entre os povos em especial através da mídia e da internet, tem levado ao recrudescimento das diferenças. Contrariamente às expectativas de Ferreira, o processo de digitalização, seja em telecentro instalado na cidade de Belém ou numa comunidade na Ilha do Marajó, pode ter como alicerce a democratização do conhecimento e das diversas culturas. Por isso, a inclusão digital é pré-condição para uma educação que vise a sustentabilidade na Amazônia. Além de manter programas estruturados de educação, o Estado precisa promover ações de inclusão digital, evidenciando um direcionamento para a inclusão social que contribua para que os pequenos produtores se apropriem de um percentual maior da renda gerada numa determinada cadeia produtiva (inegavelmente, é o caso do Grupo de Trabalho Amazônico (GTA)). Por fim, é importante reconhecer que a apropriação social da tecnologia se configura como fator de geração de trabalho e renda.

\section{Considerações finais}

É preciso estimular a construção de redes locais comunitárias que se interconectem à infraestrutura ofertada pelo Governo Federal. Estas redes podem ser geridas por conselhos, integrados pelo poder público e por representantes da sociedade civil. Sua malha poderá ser composta por um mix de tecnologias (wifi, wimax, mesh, fibra, PLC, etc.), adaptado a cada específica localidade.

Outrossim, não podemos afastar as novas possibilidades tecnológicas, sobretudo a disseminação do GNU/LINUX. As soluções de software livre devem ser consideradas como potencializadoras do processo de inclusão digital.

Dentro desta perspectiva, espera-se que surjam novos debates para que possamos dividir experiências, trazer inéditas contribuições para o desenvolvimento social, além de assegurar uma nova tomada de pensamento. Nesse sentido, experiências concretas de apropriação social da tecnologia de informação e comunicação (TIC) impulsionam metodologias nos quais se constroem os parâmetros, aliando os saberes das comunidades aos conhecimentos técnicos. 
BALBONI, M. Pesquisa sobre o uso das tecnologias da informação e da comunicação no Brasil. São Paulo: Comitê Gestor da Internet no Brasil, 2008.

FERREIRA JÚNIOR, L. P. Estado, Globalização e Integração Regional. Rio de Janeiro: América Jurídica, 2003.

FREIRE, P. Educação e Mudança. 24a. Ed. São Paulo: Paz e Terra, 2001.

LEMOS, A. Cibercultura: tecnologia e vida social na cultura contemporânea. Porto Alegre: Sulina, 2002.

LÉVY, P. A Inteligência Coletiva: por uma antropologia do ciberespaço. São Paulo: Record, 1998.

PRETTO, N. de L. Além das Redes de Colaboração: internet, diversidade cultural e tecnologias do poder. Salvador: EDUFBA, 2008.

Uma Escola sem-com Futuro: educação e multimídia. Campinas: Papirus,1986.

PRIMO, A. Interação Mediada por Computador: comunicação, cibercultura, cognição. Porto Alegre: Sulina, 2007.

REBÊLO, P. Inclusão Digital: o que é e a quem se destina? 2008. Disponível em: http// www.websinder.com.br 